\title{
Melanoma of the Anus Disguised as Hemorrhoids: Surgical Management Illustrated by a Case Report
}

\author{
M. van't Riet - R. W. M. Giard - J. H. W. de Wilt • \\ W. Vles
}

Received: 7 April 2006 / Accepted: 12 June 2006 / Published online: 6 April 2007

(C) Springer Science+Business Media, Inc. 2007

Keywords Melanoma anus · Diagnosis - Treatment - Wide local excision $\cdot$ Abdominoperineal resection

\section{Introduction}

Anal mucosal melanoma is a rare tumor that constitutes only $0.4-1.6 \%$ of all melanoma manifestations [1]. Prognosis is very poor, with a median survival of less than 2 years, despite curative surgery [2,3]. Females are more likely to be affected than males and most patients present in the sixth or seventh decade of their lives [1]. Diagnosis is not always straightforward, and is often accidental after surgical treatment for presumed benign disease such as hemorrhoidectomy or lateral internal sphincterotomy, provided that tissue is submitted to the department of pathology [4]. Unfortunately, the tumor is often widely metastasized at the time of initial diagnosis $[5,6]$. Here we present a patient who was referred to the surgeon for treatment of hemorrhoids but was diagnosed with anal melanoma.

M. van't Riet $(\bowtie) \cdot$ W. Vles

Department of Surgery, Ikazia Hospital,

Postbus 5009, 3008 Rotterdam, The Netherlands

e-mail: mvantriet@hotmail.com

R. W. M. Giard

Department of Clinical Pathology, MCRZ,

Rotterdam

J. H. W. de Wilt

Department of Surgery, Erasmus MC - Daniel Den

Hoed Cancer Center,

Rotterdam

\section{Case report}

A 62-year-old black man with a history of prostatism was referred to our hospital by his general practitioner with the diagnosis of bleeding hemorrhoids. For a 10 -week period he noticed a swelling protruding from the anus with daily bleeding from the anus. Defecation was problematical because of pain, but the stool had a normal aspect. Inspection of the anus showed a painful swelling with a diameter of $1.5 \mathrm{~cm}$ with a dark necrotic aspect surrounding the anus below the dentate line. Rectal palpation was impossible because of pain. At the outpatient department the swelling was excised under local anesthesia of the entire anus (anal block). Because of the atypical aspect of the swelling, the material was submitted for pathologic examination, which revealed a melanoma of the anus. Further staging of the tumor was not possible based on this material because of fragmentation of the tissue.

A sigmoidoscopy was performed but showed no further lesions. In addition, an abdominal and thoracic computed tomographic (CT) scan with contrast showed no signs of tumor around the anorectal region and no signs of intraabdominal, lymphatic or thoracic metastases. After the patient was diagnosed with having melanoma of the anus, examination under general anesthesia was performed. Inspection of the anal mucosa showed two additional lesions at 2 and 3 o'clock with the sacrum at 6 o'clock (Fig. 1). A wide local excision (WLE) including these lesions was performed with a margin of $2 \mathrm{~cm}$, en bloc with $25 \%$ of the circumference of the rectal wall (Fig. 1). The total excised tissue was $6 \times 7 \mathrm{~cm}$. Pathologic examination revealed two small foci of the melanoma with a depth of maximal $3.5 \mathrm{~mm}$. All margins were free of tumor. The patient recovered well from the operation. After 1-year follow-up by means of outpatient department visits and proctoscopy every 3 months, and thoracic and abdominal CT-scan twice a year, there were no signs of recurrent tumor. 


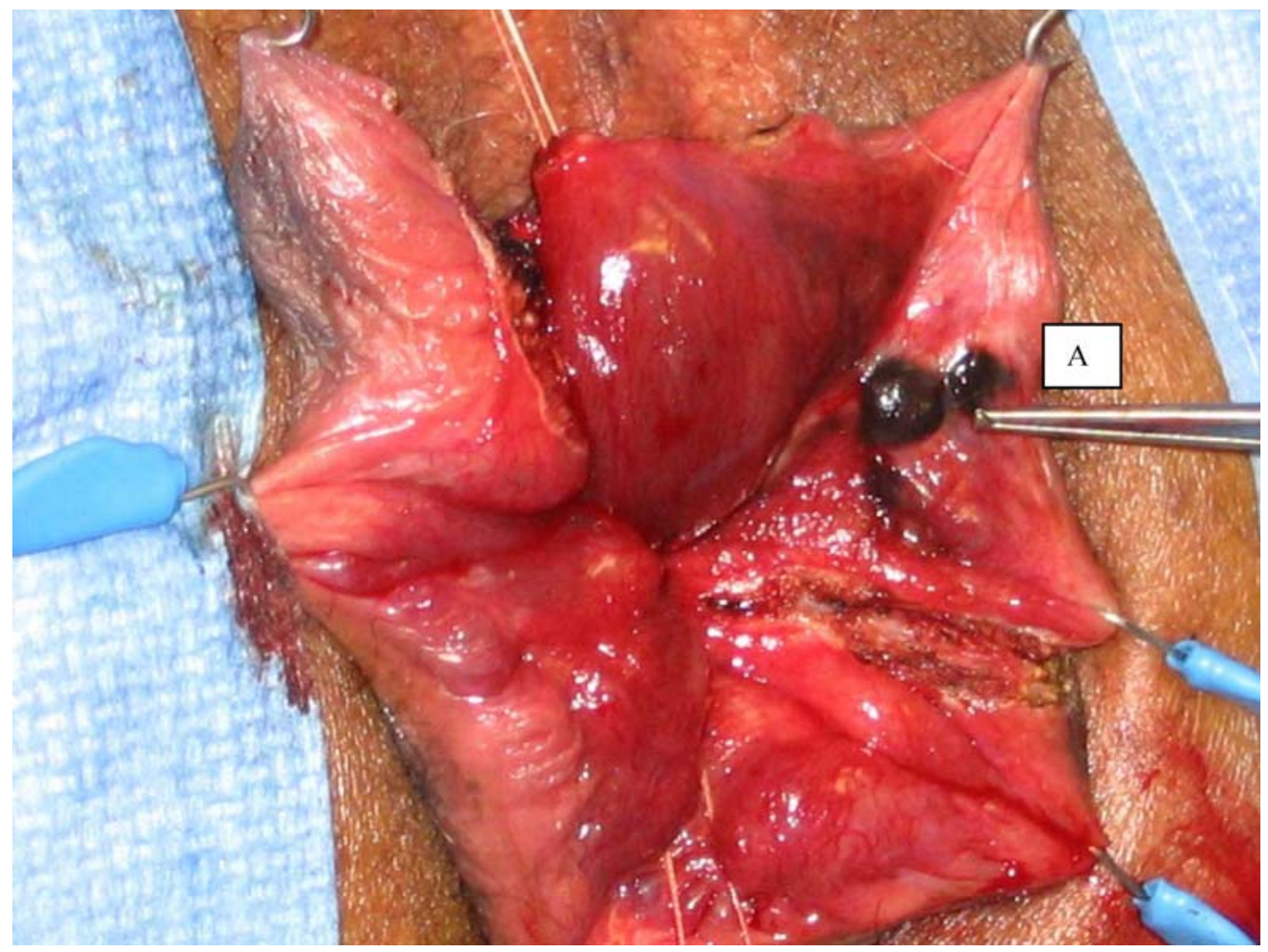

Fig. 1 Melanoma of the anus: wide local excision. A = melanoma

\section{Discussion}

Patients with anorectal melanoma usually present with symptoms of rectal bleeding and an anorectal mass and are often misdiagnosed as having hemorrhoids, as was illustrated by the present case report [4]. Therefore, on any atypical anorectal lesion, biopsy should be performed in order to prevent delayed diagnosis.

For the operative management of anorectal melanoma, two options are available: a wide local excision (WLE) or a more extensive abdominal perineal resection (APR). The choice between these surgical procedures is controversial. The main arguments in favor of APR are its ability to control lymphatic spread and to create bigger excision margins, resulting in an assumed lower local recurrence rate. But, in contrast to WLE, APR is associated with mortality, considerable postoperative morbidity (4\% hemorrhage, 11-16\% wound infection and 14-24\% wound dehiscence) and the need for a permanent colostomy [7-11].

Despite attempted curative surgery, the median survival for anorectal melanoma is only 20 months and most patients die within 5 years regardless of the type of intervention used [12]. Therefore, quality-of-life issues must be given consideration when making treatment decisions.

Droesch et al performed a systematic review of the literature, including 14 studies with a total of 301 patients [12]. Wide local excision was performed in 129 patients, and 172 patients underwent APR. Local recurrence developed in $47 \%$ of patients after WLE and in $23 \%$ of patients after APR. Although these data suggest a trend towards better locoregional control after APR, the difference was not statistically significant. In addition, there was no difference in overall survival between WLE and APR (median survival 21 months for WLE and 17 months for APR).

Bullard et al found an opposite trend with a rate of $50 \%$ of local recurrence after APR, compared to $18 \%$ after WLE in 15 patients [5]. Postoperative radiotherapy may improve locoregional control after wide local excision. In the retrospective study of Ballo et al, actuarial 5-year local control was $74 \%$ and nodal control was $87 \%$ in 23 patients who received postoperative radiotherapy after wide local excision [13]. Definitive assessment of the efficacy of adjuvant radiation therapy requires further prospective studies.

In general, it is assumed that the stage of the disease, especially the tumor thickness, is the main prognostic factor [13-15]. Therefore, Weylandt et al suggested that the decision between WLE and APR should be governed by the tumor thickness [16]. In patients with a tumor thickness below $1 \mathrm{~mm}$, a local sphincter-saving excision with $1 \mathrm{~cm}$ safety margin would be appropriate; and in cases of a tumor between 1 and $4 \mathrm{~mm}$, a wide local excision with a margin of $2 \mathrm{~cm}$ seems to be adequate. Patients with a tumor thickness above $4 \mathrm{~mm}$ or invasion of the internal sphincter muscle should be treated with APR. In the case report mentioned 
in this article, the tumor depth was $3.5 \mathrm{~mm}$ and excision margins were free of tumor, thus no additional APR was performed.

In order to evaluate the deepness of the lesion preoperatively, endorectal ultrasonography can be performed [6]. Accuracy in evaluating tumor depth of rectal cancer ranges from 81 to $94 \%$, and accuracy in detecting lymph node metastasis ranges from 58 to $80 \%$ [17]. However, its accuracy in evaluation of anorectal melanoma remains unproved and is still evaluated [5].

At the time of diagnosis, up to one-third (16-33\%) of the patients have disseminated disease [3]. For these patients, palliative treatment with chemotherapy might be a treatment option. Kim et al reported a series of 18 patients with metastatic anorectal melanoma treated with cisplatin, vinblastine, dadabazine, interferon alpha- $2 \mathrm{~b}$ and interleukin2 [18]. Major response was seen in $44 \%$ of the patients, and complete response occurred in $11 \%$, with a median overall survival of 12.9 months. Yeh et al used a different treatment regimen of temozolomide, cisplatin and liposomal doxorubicin in a patient with stage IV anal mucosal melanoma [19]. This patient showed a remarkable response to chemotherapy, with minimal residual disease and excellent quality of life at 12 months after the start of treatment. However, this therapy still has to be further evaluated and currently no standard systemic therapeutic regimen exists for metastatic anorectal melanoma.

In conclusion, anorectal melanoma represents both a diagnostic and therapeutic challenge to physicians given its non-specific presentation and rarity. It is associated with poor prognosis, regardless of the type of intervention used. Therefore, the overall treatment goal should be to optimize the quality of life. Since wide local excision is a more limited intervention associated with at least comparable survival compared to APR and no need for permanent colostomy, wide local excision is recommended as primary therapy if negative surgical margins can be achieved. APR should be reserved for patients in whom the tumor is thicker than $4 \mathrm{~mm}$ and/or involves the anal sphincter.

\section{References}

1. Wanebo HJ, Woodruff JM, Farr GH, Quan SH (1981) Anorectal melanoma. Cancer 47:1891-1900
2. Brady MS, Kavoliu JP, Quan SH (1995) Anorectal melanoma: a 64-year experience at Memorial Sloan-Kettering Cancer Center. Dis Colon Rectum 38:146-151

3. Thibault C, Sagar P, Nivatvongs S, Ilstrup DM, Wolff BG (1997) Anorectal melanoma: an incurable disease? Dis Colon Rectum 40:661-668

4. Pessaux P, Pocard M, Elias D, Duvillard P, Avril MF, Zimmerman P, et al (2004) Surgical management of primary anorectal melanoma. Br J Surg 91:1183-1187

5. Bullard KM, Tuttle TM, Rothenberger DA, Madoff RD, Baxter NN, O'Finne C, Spencer MP (2003) Surgical therapy for anorectal melanoma. Am Coll Surg 196:206-211

6. Malik A, Hull TL, Floruta C (2004) What is the best surgical treatment for anorectal melanoma. Int J Colorectal Dis 19:121123

7. Rothenberger DA, Wond WD (1992) Abdominoperineal resection for adeocarcinoma of the low rectum. World J Surg 16:478-485

8. Petrelli NJ, Nagel S, Rodriguez-Bigas M, et al (1993) Morbidity and mortality following abdominoperioneal resection for rectal adenocarcinoma. Am Surg 59:400-404

9. De Canniere L, Rosiere A, Michel LA (1993) Synchronous abdominoperineal resection without transfusion. Br J Surg 80:11941195

10. Pollard CW, Nivatvongs S, Rojanasakul A, Ilstrup DM (1994) Carcinoma of the rectum. Profiles of intraoperative and early postoperative complications. Dis Colon Rectum 37:866-874

11. MacKeigan JM, Catalso PA (1996) Abdominoperineal resection. In: Hicks TC, Opelka FG, Timmcke AE (eds) Complications of colon and rectal surgery. Williams \& Wilkins, Baltimore, pp 312338

12. Droesch JT, Flum DR, Mann GN (2005) Wide local excision of abdominoperineal resection as the initial treatment for anorectal melanoma. Am J Surg 189:446-449

13. Ballo MT, Gershenwald JE, Zagars GK, et al (2002) Sphinctersparing local excision and adjuvant radiation for anal-rectal melanoma. J Clin Oncol 20:4555-4558

14. Slingluff CL, Vollmert RT, Seigler HF (1990) Anorectal melanoma: characteristics and results of surgical management in twenty-four patients. Surgery 107:1-9

15. Goldman S, Glimelius B, Pahlman L (1990) Anorectal malignant melanoma in Sweden: report of 49 patients. Dis Colon Rectum 33:874-877

16. Weyandt GH, Eggert AO, Houf M, Faulf F, Bröcker EB, Becker JC (2003) Anorectal melanoma: surgical management guidelines according to tumour thickness. Br J Cancer 89:20192022

17. Phang PT, Wong WD (1997) The use of endoluminal ultrasound for malignant and benign anorectal diseases. Curr Opin Gastroenterol $13: 47-53$

18. Kim KB, Sanguino AM, Hodges C, Papadopoulos NE, Eton O, Camacho LH, et al (2004) Biochemotherapy in patients with metastatic anorectal mucosal melanoma. Cancer 100:1478-1483

19. Yeh JJ, Weiser MR, Shia JS, Hwu JW (2005) Response of stage IV anal mucosal melanoma to chemotherapy. Lancet Oncol 6:438439 